\title{
Socioeconomic Indicators, Tobacco and Alcohol in the Aetiology of Digestive Tract Neoplasms
}

\author{
MONICA FERRARONI*, EVA NEGRI**, CARLO LA VECCHIA**, + BARBARA D'AVANZO** \\ AND SILVIA FRANCESCHI‡
}

\begin{abstract}
Ferraroni M (Institute of Medical Statistics, University of Milan, 20133 Milan, Italy), Negri E, La Vecchia C, D'Avanzo B and Franceschi S. Socioeconomic indicetors, tobacco and alcohol in the aetiology of digestive tract neoplesms. International Journal of Epidemiologr 1989, 18: 556-562.

The redationship between education, social class, smoking habits, alcohol consumption and the risk of digestive tract neoplasms was analysed in a case-control study of 50 cases of cancer of the mouth or pharynx, 209 of the oesophagus. 397 of the stomach, 455 of the colon, 295 of the rectum, 151 of the liver, 214 of the pancreas, and a total of 1944 control subjects admitted for acute, non-neoplastic or digestive tract disorders. Cancers of the mouth or pharynx, oesophagus and stomach were inversely and strongly related to education, with risk estimates ranging between 0.2 and 0.4 for the highest education categories. Significant, but weaker inverse relations were evident for rectal and liver cancer, too, whereas the risk of colon cancer was elevated among more educated individuals. There was no relationship between education and pancreatic cancer. The pattern of risk was largely comparable when the head of the household's occupation was used as indicator of social class. There were strong direct associations between cigarette (as well as pipe or cigarl smoking and cancers of the mouth or pharynx and cesophagus, and a moderate one with pancreatic cancer, but none of the other sites considered was related to smoking habits. Cancers of the mouth or pharynx and oesophagus were independently and strongly related to alcohol consumption, too, while the associations between alcohol and liver or pancreatic cancer were moderate and not significant. Cancers of the stomach, colon and rectum were unrelated to measures of alcohol consumption.
\end{abstract}

Social class and widespread lifestyle habits, such as tobacco and alcohol consumption, are important determinants of most diseases, including cancers of the digestive tract. ${ }^{1-4}$ Their role and interaction, however, are probably heterogeneous in different populations, in relation to the different combinations of exposure to risk factors.

This article presents the comparative pattern of risks of various digestive tract cancers in relation to socioeconomic indicators, alcohol and tobacco, on the basis of data from a series of case-control studies conducted in Northern Italy.

\section{SUBJECTS AND METHODS}

The present data were derived from an ongoing casecontrol study of several neoplasms of the digestive tract,

\footnotetext{
* Insilute of Medical Statisics, University of Milan, 20133 Milan, lialy.

** "Mario Negri" Institute for Pharmacological Research, 20157 Milan, Italy.

t Instilute of Social and Preventive Medicine, Universily of Lausanne, 1005 Lausanne, Suizzerland.

F Oncological Refertal Centre, 33081 Aviano, Pordenone, lialy. Reprint requests: Carlo La Vecchia, Istituto di Richerche Farmacologiche "Mario Negri", Via Eritrea, 62, 20157 Milan, Italy.
}

based on a network of teaching and general hospitals from the Greater Milan area. Recruitment of cases of various cancers started between 1983 and 1985, and the present report is based on data collected up to March 1988.

The general design of this investigation has already been described. ${ }^{5.6}$ Briefly, trained interviewers identified and questioned patients admitted to university and general hospitals in the area under surveillance for various cancers of the digestive tract and for a wide spectrum of other conditions. On average, less than $2 \%$ of eligible subjects (cases and controls) refused to be interviewed. All interviews were conducted in hospital. Selected sections of the interview were repeated by telephone a few weeks later on a subsample of approximately $10 \%$ of cases and controls. This was done to check the reproducibility and reliability of the questionnaire and interviews.

\section{Cases}

The cases studied were subjects below the age of 75 , with histologically confirmed cancers of the digestive tract diagnosed within the year preceding the interview, who had been admitted to the National Cancer Institute, to several university clinics (chiefly surgical) 
and to the Ospedale Maggiore, which includes the four largest teaching and general hospitals in Milan.

Included in the present analyses were cancers of the mouth or pharynx $(n=50)$, oesophagus $(n=209)$, stomach $(n=397)$, colon $(n=455)$, rectum $(n=295)$, liver $(n=151)$ and pancreas $(n=214)$.

\section{Controls}

Patients admitted for a wide spectrum of acute conditions to several specialized university clinics and to the Ospedale Maggiore of Milan were eligible as controls. None of these patients had malignant tumours, digestive-tract disorders or any condition related to coffee, alcohol and tobacco consumption, or which might have resulted in long-term modification of diet. A total of 1944 controls (1334 males, 610 females) were interviewed. Of these, $38 \%$ were admitted for traumatic conditions (mostly fractures and sprains), $15 \%$ had non-traumatic orthopaedic disorders (mostly lower back pain and disc disorders), $34 \%$ were admitted for acute surgical conditions (including plastic surgery) and $13 \%$ had other illnesses, such as ear, nose and throat, skin or dental disorders. The median age of the comparison group was 56 years, and the distribution of cases and controls according to age and sex is given in Table 1. The catchment areas of cases and controls were well comparable. Overall, $86 \%$ of the cases and $83 \%$ of the controls resided in the same region, Lombardy; $6 \%$ of the cases and $4 \%$ of the controls came from other Northern Italian regions; $8 \%$ of the cases and $13 \%$ of the controls from Central or Southern ltaly.

A standard questionnaire was used to obtain information on sociodemographic factors and general characteristics and habits, including smoking, alcohol, coffee and other methylxanthine-containing beverage consumption; a brief dietary history based on 33 indicator foods; related personal and family medical history; and history of use of selected drugs.
All information referred to the situation before to the onset of the disease which led to hospital admission. More specifically, the definition of social class was based on the head of the household's occupation, with a classification derived from that used by the British Registrar General,,$^{7,8}$ and reclassified in three levels only (low, corresponding to the Registrar General's social classes IV and V, intermediate, corresponding to social class III, and high, corresponding to I and II).

Information on smoking included smoking status (never/ex/current) smoker age at starting, the types of products (cigarettes, pipe or cigars) smoked, the amount smoked per day before the onset of the disease, the period of smoking and (for cigarette smokers) the cigarette brand(s) smoked for the longest time.

The questions on alcohol included the number of days per week on which wine, beer and spirits were consumed, the current (ie, before the onset of symptoms of the index disease) average number of drinks per day, and the total duration (in years) of consumption of each type of alcoholic beverage.

\section{Data Analysis and Control of Confounding}

Relative risks (RR) of various digestive tract neoplasms, together with their $95 \%$ approximate confidence intervals $(\mathrm{Cl})$, were first derived from data stratified for sex and age decades. ${ }^{9}$ Secondly, to account simultaneously for the potential reciprocal confounding effects of several factors, unconditional multiple logistic regression equations were fitted, ${ }^{10}$ including terms for social class, education, marital status, smoking and alcohol consumption, besides age and sex. Dose gradients in the logistic models were based on chisquare values for trend, computed as the difference between the deviances of the models without and the deviances of the models including the variable of interest.

TABLE 1 Distribution of selected digestive tract cancers and controls according to sex and age. Milan, Italy, 1983-88.

\begin{tabular}{|c|c|c|c|c|c|c|c|c|c|}
\hline \multirow[b]{2}{*}{ Type of cancer } & \multicolumn{4}{|c|}{ Males, age group } & \multicolumn{4}{|c|}{ Females, age group } & \multirow[b]{2}{*}{ Total } \\
\hline & $<45$ & $45-54$ & $55-64$ & $65-74$ & $<45$ & $45-54$ & $55-64$ & $65-74$ & \\
\hline Mouth or pharynx & 1 & 24 & 12 & 6 & 1 & 3 & 3 & - & 50 \\
\hline Oesophagus & 10 & 46 & 71 & 35 & 5 & 8 & 19 & 15 & 209 \\
\hline Stomach & 21 & s) & 85 & 86 & 14 & 31 & 52 & 57 & 397 \\
\hline Colon & 22 & 36 & 77 & 86 & 19 & 45 & 75 & 95 & 455 \\
\hline Rectum & 12 & 27 & 65 & 66 & 8 & 18 & 45 & 54 & 295 \\
\hline Liver & 12 & 19 & 54 & 30 & 8 & 6 & 12 & 10 & 151 \\
\hline Pancreas & 11 & 37 & 47 & 41 & 4 & 11 & 28 & 35 & 214 \\
\hline Controls & 276 & 392 & 384 & 282 & 69 & 127 & 218 & 196 & 1944 \\
\hline
\end{tabular}




\section{RESULTS}

The distribution of cases of various digestive sites and of the comparison group according to socioeconomic indicators, tobacco and alcohol consumption is given in Table 2. Corresponding relative risk estimates are reported in Tables 3 (education), 4 (social class), 5 (tobacco) and 6 (alcohol).

Cancers of the mouth or pharynx, oesophagus and stomach were inversely and strongly related to education, with point estimates ranging between 0.2 and 0.4 for individuals with 12 years of education or more as compared with less than seven. Significant (although weaker) inverse relations with measures of education were evident for rectal and liver cancer, too, whereas colon cancer was slightly more frequent among more educated individuals, the trend in risk being of borderline significance. There was no relation between education and the risk of pancreatic cancer (Table 3 ).

The pattern observed for the other socioeconomic indicat or considered, ie social class based on the head of the household's occupation, was largely (but not totally) similar to that of education. There were, in fact, inverse social class gradients for cancers of the mouth or pharynx, oesophagus, stomach, rectum and liver, and a direct gradient for colon cancer. Using this indicator,
TABLE 3 Relative risk of selected digestive iract cancers according to education. Milan, Italy, 1983-88.

\begin{tabular}{|c|c|c|c|c|c|}
\hline \multirow[b]{2}{*}{ Type of cancer } & \multirow[b]{2}{*}{ Model } & \multicolumn{3}{|c|}{ Education (years) } & \multirow{2}{*}{$\begin{array}{c}x 1^{2} \\
\text { (trend) }\end{array}$} \\
\hline & & $<7$ & $7-11$ & $\geq 12$ & \\
\hline \multirow[t]{2}{*}{ Mouth or pharynx } & $\mathbf{a}$ & $1 \#$ & 0.29 & 0.16 & $20.89^{* *}$ \\
\hline & b & $1:$ & 0.36 & 0.19 & $15.37^{* *}$ \\
\hline \multirow[t]{2}{*}{ Oesophagus } & $a$ & $1 \%$ & 0.50 & 0.36 & $28.79 \cdot 4$ \\
\hline & b & $1 \%$ & 0.54 & 0.40 & $23.44^{* * *}$ \\
\hline \multirow[t]{2}{*}{ Stomach } & a & $1 \#$ & 0.63 & 0.35 & $41.42 * *$ \\
\hline & b & $1 \sharp$ & 0.64 & 0.35 & $39.35 * *$ \\
\hline \multirow[t]{2}{*}{ Colon } & $\mathbf{a}$ & 14 & 1.05 & 1.20 & 1.58 \\
\hline & b & J & 1.15 & 1.32 & 3.37 \\
\hline \multirow[t]{2}{*}{ Rectum } & $\mathbf{a}$ & $1 \#$ & 0.74 & 0.63 & $8.16^{* *}$ \\
\hline & b & $1 \#$ & 0.78 & 0.65 & $6.21^{*}$ \\
\hline \multirow[t]{2}{*}{ Liver } & $\mathbf{a}$ & $1 \#$ & 0.70 & 0.54 & $7.95 * *$ \\
\hline & b & $1 H$ & 0.76 & 0.59 & $5.93^{*}$ \\
\hline \multirow[t]{2}{*}{ Pancreas } & $\mathbf{a}$ & $1 \#$ & 0.88 & 0.85 & 0.89 \\
\hline & b & $1 \#$ & 0.90 & 0.92 & 0.80 \\
\hline
\end{tabular}

(a) Erimates adjusted for age and sex only.

(b) Estimates from multiple logistic regression including terms for age, sex, education, marital status, smoking, coffee and alcohol consumption.

Reference category.

* $p<0.05 ; \quad * p<0.01$.

TABLE 2 Distribution of selected digestive tract cancers and controls according to the risk factors considered. Milan, Italy, $1983-88$.

\begin{tabular}{|c|c|c|c|c|c|c|c|c|}
\hline & \multicolumn{7}{|c|}{ Cancers of the: } & \multirow[b]{2}{*}{ Controls } \\
\hline & pharynx & Oesophagus & Stomach & Colon & Rectum & Liver & Pancreas & \\
\hline \multicolumn{9}{|l|}{ Education (years) } \\
\hline$<7$ & 40 & 148 & 272 & 239 & 187 & 94 & 122 & 936 \\
\hline $7-11$ & 7 & 39 & 88 & 120 & 66 & 36 & 53 & 562 \\
\hline 212 & 3 & 22 & 37 & 96 & 42 & 21 & 39 & 426 \\
\hline \multicolumn{9}{|l|}{ Social classt } \\
\hline I or II (highest) & 3 & 9 & 10 & 45 & 24 & 7 & 35 & 180 \\
\hline III & 9 & s5 & 121 & 155 & 69 & 49 & 61 & 683 \\
\hline IV or V (lowest) & 27 & 115 & 194 & 170 & 146 & 70 & 88 & 827 \\
\hline other or undefined & 11 & 30 & 72 & 85 & 56 & 25 & 30 & 254 \\
\hline \multicolumn{9}{|l|}{ Smoking habits } \\
\hline Never smokers & $s$ & 33 & 181 & 275 & 156 & 64 & 89 & 795 \\
\hline Ex smokers & 2 & 41 & 73 & 75 & 57 & 36 & 49 & 380 \\
\hline Pipe/cigar smokers & 1 & 5 & 3 & 1 & 2 & - & - & 11 \\
\hline Cigarette smokers, & & & & & & & & \\
\hline$<15 /$ day & 5 & 35 & 48 & 37 & 27 & 19 & 19 & 267 \\
\hline $15-24 /$ day & 25 & 56 & 63 & 48 & 34 & 21 & 42 & 332 \\
\hline$\geq 25 /$ day & 12 & 39 & 29 & 19 & 19 & 11 & 15 & 159 \\
\hline \multicolumn{9}{|c|}{$\begin{array}{l}\text { Total alcohol consumption, } \\
\text { drinks pet day }\end{array}$} \\
\hline$<3$ & 11 & 63 & 223 & 290 & 187 & 78 & 112 & 1065 \\
\hline $3-6$ & 11 & 52 & 99 & 107 & 62 & 34 & 59 & 558 \\
\hline$>6$ & 28 & 94 & 75 & 58 & 46 & 39 & 43 & 321 \\
\hline
\end{tabular}

t Based on the head of the houschold's occupation. 
TABLE 4 Relative risk of selected digestive Iract cancers occording to social class. ${ }^{\dagger}$ Milan, IIaly. 1983-88.

\begin{tabular}{|c|c|c|c|c|c|c|}
\hline Type of cancer & Model & $\begin{array}{l}\text { IV or V } \\
\text { (lowest) }\end{array}$ & $\begin{array}{c}\text { Social class } \\
\text { III } \\
\text { (intermediate) }\end{array}$ & $\begin{array}{c}\text { I or II } \\
\text { (highest) }\end{array}$ & $\begin{array}{l}\text { Other or } \\
\text { undefined }\end{array}$ & $\begin{array}{c}x 1^{2 \neq} \\
\text { (trend) }\end{array}$ \\
\hline \multirow[t]{2}{*}{ Mouth or pharynx } & a & 18 & 0.43 & 0.50 & 1.66 & $4.89^{*}$ \\
\hline & b & $1 \#$ & 0.50 & 0.69 & 1.48 & 2.42 \\
\hline \multirow[t]{2}{*}{ Oesophagus } & a & $1 \#$ & 0.60 & 0.38 & 0.89 & $14.42 * *$ \\
\hline & b & $1 \%$ & 0.66 & 0.45 & 0.95 & $8.30^{* *}$ \\
\hline \multirow[t]{2}{*}{ Stomach } & a & $1 \#$ & 0.79 & 0.24 & 1.02 & $20.09 * *$ \\
\hline & b & 17 & 0.81 & 0.24 & 1.13 & $17.68^{* *}$ \\
\hline \multirow[t]{2}{*}{ Colon } & a & $1 \#$ & 1.15 & 1.34 & 1.23 & 2.59 \\
\hline & b & $1 \#$ & 1.22 & 1.40 & 1.27 & 3.83 \\
\hline \multirow[t]{2}{*}{ Rectum } & $\mathrm{a}$ & $1 \%$ & 0.60 & 0.79 & 1.00 & $6.01^{*}$ \\
\hline & b & $1 \#$ & 0.61 & 0.82 & 0.99 & $4.54^{*}$ \\
\hline \multirow[t]{2}{*}{ Liver } & $\mathbf{a}$ & $1 \%$ & 0.87 & 0.50 & 1.21 & 2.72 \\
\hline & b & 1 日 & 0.92 & 0.54 & 1.24 & 2.02 \\
\hline \multirow[t]{2}{*}{ Pancreas } & $\mathbf{a}$ & $1 H$ & 0.88 & 1.87 & 0.63 & 3.69 \\
\hline & b & $1 H$ & 0.63 & 1.29 & 0.63 & $4.03^{*}$ \\
\hline
\end{tabular}

† Based on the head of the household's occupation.

\# Other or undefined excluded.

(a) Estimates adjusted for age and sex only.

(b) Estimates from multiple logistic regression including terms for age, sex, social class, marital status, smoking, coffee and alcohol consumption.

\# Reference category.

* $p<0.05 ; \quad$ ** $p<0.01$.

TABLE 5 Relative risk of selected digestive tract cancers according to smoking habits. Milan, Italy. 1983-88.

\begin{tabular}{|c|c|c|c|c|c|c|c|c|}
\hline \multirow[b]{2}{*}{ Types of cancer } & \multirow[b]{2}{*}{ Model } & \multicolumn{6}{|c|}{ Smoking habits } & \multirow[b]{2}{*}{$\begin{array}{c}x 1^{2+} \\
\text { (trend) }\end{array}$} \\
\hline & & $\begin{array}{l}\text { Never } \\
\text { smokers }\end{array}$ & $\begin{array}{c}\text { Ex } \\
\text { smokers }\end{array}$ & $\begin{array}{l}\text { Pipe/cigar } \\
\text { smokers }\end{array}$ & $<15 /$ day & $\begin{array}{l}\text { igarete smoke } \\
15-24 / \text { day }\end{array}$ & $\geq 25 /$ day & \\
\hline \multirow[t]{2}{*}{ Mouth or pharynx } & $\mathbf{a}$ & $1 \#$ & 0.78 & 16.25 & 2.90 & 11.02 & 10.98 & $28.63^{* *}$ \\
\hline & b & $1 \#$ & 0.91 & 44.91 & 3.64 & 11.06 & 10.80 & $25.53 * 4$ \\
\hline \multirow[t]{2}{*}{ Oesophagus } & a & $1 *$ & 2.71 & 13.49 & 3.59 & 4.65 & 7.57 & $56.40^{* *}$ \\
\hline & $\mathbf{b}$ & $1 \#$ & 2.88 & 19.35 & 4.24 & 4.19 & 7.22 & $45.67^{* *}$ \\
\hline \multirow[t]{2}{*}{ Stomach } & $\mathbf{a}$ & $1 n$ & 0.90 & 1.35 & 0.93 & 1.04 & 1.10 & 0.18 \\
\hline & $\mathbf{b}$ & $1 \theta$ & 0.93 & 2.00 & 1.02 & 1.01 & 1.14 & 1.19 \\
\hline \multirow[t]{2}{*}{ Colon } & $\mathbf{a}$ & $1 \sharp$ & 0.72 & 0.37 & 0.62 & 0.70 & 0.85 & 1.42 \\
\hline & b & 11 & 0.73 & 0.36 & 0.65 & 0.76 & 0.83 & 1.78 \\
\hline \multirow[t]{2}{*}{ Rectum } & $\mathbf{a}$ & 19 & 0.78 & 1.10 & 0.61 & 0.66 & 0.89 & 2.37 \\
\hline & b & $1 *$ & 0.85 & 1.35 & 0.68 & 0.75 & 1.07 & 0.90 \\
\hline \multirow[t]{2}{*}{ Liver } & a & $1 *$ & 0.87 & - & 0.75 & 0.64 & 0.73 & 1.89 \\
\hline & b & $1 \%$ & 0.94 & - & 0.85 & 0.68 & 0.78 & 1.35 \\
\hline \multirow[t]{2}{*}{ Pancreas } & a & 18 & 1.23 & - & 0.75 & 1.16 & 1.44 & 1.74 \\
\hline & b & 18 & 1.23 & - & 0.76 & 1.15 & 1.42 & 1.25 \\
\hline
\end{tabular}

+ Never and current cigarette smokers only.

- Reference category.

(a) Estimates adjusted for age and sex only.

(b) Estimates from multiple logistic regression including terms for age, sex, education, marital status, smoking, coffee and alcohol consumption. ** $p<0.01$. 
the risk of pancreatic cancer was somewhat elevated in the highest social class, too, although the pattern of risk was not linear across categories of social class (Table 4).

Smoking habits are considered in Table 5. There were strong positive associations between cigarettes (as well as cigars and pipe) and cancers of the mouth or pharynx and oesophagus, but none of the other sites considered was significantly related to tobacco. The point estimates for cigarette smoking were somewhat above unity for stomach and pancreas, and below unity for colo-rectum and liver, but no consistent trend was observed.

Total alcoholic beverage consumption is presented in Table 6. In this case, too, there were strong positive and independent relations with cancers of the upper digestive tract (mouth or pharynx and oesophagus). There was some inconsistent and moderate association (not statistically significant) with liver and pancreatic cancers, whereas cancers of the stomach, colon and rectum appeared unrelated to measures of alcohol consumption. Separate examination of the three types of alcoholic beverages (wine, beer and spirits) showed no noticeable pattern, possibly since the large majority (almost $90 \%$ ) of all alcohol intake in this population was accounted for by wine alone.

TABLE 6 Relarive risk of selected digestive tract cancers according to average total daily alcohol consumption. Milan, Italy, 1983-88.

\begin{tabular}{|c|c|c|c|c|c|}
\hline \multirow[b]{2}{*}{ Type of cancer } & \multirow[b]{2}{*}{ Model } & \multicolumn{3}{|c|}{$\begin{array}{l}\text { Total alcohol consumption } \\
\text { (drinks per day) }\end{array}$} & \multirow{2}{*}{$\begin{array}{c}x_{1}^{2} \\
\text { (trend) }\end{array}$} \\
\hline & & $<3$ & $3-6$ & $>6$ & \\
\hline \multirow[t]{2}{*}{ Mouth or pharynx } & a & $1 \#$ & 1.38 & 6.81 & $26.73^{* *}$ \\
\hline & b & $1 H$ & 1.64 & 3.82 & $14.75^{* *}$ \\
\hline \multirow[t]{2}{*}{ Oesophagus } & $\mathbf{a}$ & $1 \#$ & 1.71 & 5.46 & $71.15^{* *}$ \\
\hline & b & $1 \#$ & 1.57 & 4.29 & $49.94^{* *}$ \\
\hline \multirow[t]{2}{*}{ Stomach } & a & $1 *$ & 0.99 & 1.35 & 2.43 \\
\hline & $\mathbf{b}$ & $1 \#$ & 0.96 & 1.16 & 0.55 \\
\hline \multirow[t]{2}{*}{ Colon } & a & $1 \#$ & 1.04 & 1.09 & 0.23 \\
\hline & b & $1 \#$ & 1.06 & 1.16 & 0.67 \\
\hline \multirow[t]{2}{*}{ Rectum } & a & $1 \%$ & 0.74 & 0.99 & 0.27 \\
\hline & $b$ & $1 甘$ & 0.78 & 0.92 & 0.46 \\
\hline \multirow[t]{2}{*}{ Liver } & a & 1* & 0.72 & 1.41 & 1.26 \\
\hline & $\mathbf{b}$ & $1 *$ & 1.04 & 1.35 & 0.86 \\
\hline \multirow[t]{2}{*}{ Pancreas } & $\mathbf{a}$ & $1 *$ & 1.16 & 1.51 & 3.39 \\
\hline & $\mathbf{b}$ & $1 *$ & 1.14 & 1.46 & 2.89 \\
\hline
\end{tabular}

(a) Estimates adjusted for age and sex only.

(b) Estimates from multiple regression including terms for age, sex, social class, education, marital status, smoking, coffee and alcohol consumption.

$\#$ Reference category.

** $p<0.01$.

\section{DISCUSSION}

The results of this integrated series of case-control studies are in agreement with several epidemiological clues to digestive tract cancers. In particular, they confirm that there are strong inverse social class gradients for cancers of the mouth or pharynx, oesophagus and stomach, ${ }^{1.11,12}$ and that neoplasms of the upper digestive tract (mouth, pharynx and oesophagus) are strongly and independently related both to alcohol and various forms of tobacco. 3.4,13.14

Moreover, they provide further information of interest for areas still open to debate. For instance, the inverse social gradient for liver cancer, even after allowance for alcohol, may well open wider perspectives for understanding the aetiological correlates of hepatocellular carcinoma in various populations in terms for instance of exposure to hepatitis B virus, chemical carcinogens or diet.$^{15-17}$ Likewise, the different pattern of risk in relation to social class indicators for colon (positive) or rectal (negative) cancers may shed light on different aetiological determinants of the two intestinal subsites. ${ }^{18}$

In this study, there are a number of negative results which deserve careful consideration. There was no association between smoking and liver cancer, and only moderate non-significant associations between alcohol and liver, or smoking, alcohol and pancreas. Beer consumption was uncommon in this population, since only about $10 \%$ of the controls drank one, and $4 \%$ more than one beer per day. This study had, therefore, limited power to consider the possible relation between beer and rectal cancer, found in some $e^{19-21}$ but not other studies. ${ }^{22-24}$

It is possible that the absence of some associations is due to limitations of the study, and possibly to the fact that it was not population-based, or to the utilization of hospital controls, which is still open to debate as far as analyses of lifestyle habits are concerned. However, information derived from a nationwide household health survey indicated that ex-rather than current smokers tended to be admitted to hospital more frequently, and to stay longer in the hospital, and (probably as a consequence of selection effects), there is no direct relation between amount smoked and hospital stay. ${ }^{25}$ Further, a priori excluded from the comparison group were all chronic conditions, any disease related to alcohol or tobacco (including alcoholrelated trauma), and accurate checks were made of the consistency of variables considered across broader categories of controls (orthopaedics, surgical and other miscellaneous). In relation to other potential sources of bias, cases and controls came from comparable catchment areas, were interviewed in similar settings, and, 
with reference to the variables considered in this article, no appreciable problem of reproducibility and reliability emerged from the routine validation of a subsample of the interviews. As regards possible confounding bias, reciprocal allowance was made for major potential distorting factors in multivariate analyses, and further inclusion of terms for available indicator foods did not materially modify the estimated risks.

An important and interesting aspect of this study lies, in our opinion, in the possibility of simultaneous description and analysis of the overall pattern of risk for several digestive tract neoplasms, permitting internal comparisons and checks for consistency between various risks. A similar approach was adopted in a population-based case-control study in France ${ }^{3}$ which showed elevated risks for alcohol and tobacco consumption in relation to oesophageal cancer, but risks close to unity for all other digestive tract neoplasms. In that study, the absence of association between tobacco and pancreatic cancer or alcohol and liver cancer was explained in terms of heterogeneity in smoking habits and patterns in various populations. Likewise, no relation with tobacco, and only a moderate association with alcohol were found in a case-control study of liver cancer conducted in Southern Italy. ${ }^{26}$

The results of the present study could be interpreted along the same lines of different patterns of exposure and risk in different populations, although they are still compatible with some moderate association between alcohol, tobacco and cancers of the pancreas and liver, ${ }^{15,16,27-29}$ however one order of magnitude smaller than for neoplasms of the upper digestive tract.

\section{ACKNOWLEDGEMENTS}

This work was conducted within the framework of the CNR (Italian National Research Council) Applied Project "Oncology" (Contract No 87.01544.44). The contributions of the Italian League Against Tumours and of the Italian Association for Cancer Research, Milan, Italy, are gratefully acknowledged. We wish to thank Ms Judy Baggott, Gigliola Brambilla Pisoni and the G A Pfeiffer Memorial Library Staff for editorial assistance.

\section{REFERENCES}

I Pukkala E, Teppo L. Socioeconomic status and education as risk determinants of gastrointessinal cancer. Prev Med 1986; 15: 127-38.

2 Papadimitriou C, Day N, Tzonou A, Gerovassilis F, Manousos $O$. Trichopoulos D. Biosocial correlates of colorectal cancer in Greece. InI J Epiderniol 1984; 13: 155-9.

3 Tuyns A J, Pequignot G, Gignoux M, Valla A. Cancers of the digestive tract, alcohol and tobacco. Int J Cancer 1982; 30: 9-11.
4 Elwood J M, Pearson J C G, Skippen D H, Jackson S M. Alcohol, smoking, social and occupational factors in the aetiology of cancer of the oral cavity, pharynx and larynx. Int J Concer 1984; 34: $603-12$

$\checkmark$ La Vecchia C, Liati P, Decarli A, Negrello I, Franceschi S. Tar yields of cigarettes and the risk of oesophageal cancer. InI $J$ Cancer 1986; 38: $381-5$.

${ }^{6}$ La Vecchia C, Negri E, Decarli A, D'Avanzo B, Gallotti L, Gentile A, Franceschi S. A case-control study of diet and colorectal cancer in northern Italy. Int $J$ Cancer 1988; 41: 492-8.

7 Townsend P, Davidson N. Inequalities in Healih: The Black Report. Harmondsworth, Penguin, 1982.

8 Office of Population Censuses and Surveys. Occupational mortality, 1970-80, 1982-83: Decennial supplement. London, HMSO, 1986.

9 Breslow N E, Day N E. Stalistical inethads in cancer research. Vol. I. The analysis of case-control studies. Lyon, IARC, 1980.

10 Baker R J, Netder J A. The GLIM system. Release 3. Oxford, Numerical Algorithms Group (1978).

11 Logan W P D. Cancer mortality by occupation and social class, 1851-1971. IARC Sci Publ 1982; 36.

12 Cuello C, Correa P, Haenszel W. Socio-economic class differences in cancer incidence in Cali, Colombia. Int J Cancer 1982; 29: 637-43.

13 Jensen O M. Cancer morbidity and causes of death among Danish Brewery Workers. Int J Cancer 1979; 23: 454-63.

14 Tuyns A J, Pequignot G. Jensen O M. Le cancer de l'oesophage en Ille-et-Vilaine en fonction des niveaux de consommation d'alcool et de tabac. Des risques qui se multiplient. Bull Cancer 1977; 64: 45-60.

15 Editorial. Hepatocellular cancer: Differences between high and low incidence regions. Lancet 1987; 2: 1183-4.

16 Trichopoulos D, Day N E, Kaklamani E, Tzonou A, Munoz N, Zavitsanos X, Koumantaki $Y$, Trichopoulou A. Hepatitis B virus, tobacco smoking and ethanol consumption in the etiology of hepatocellular carcinoma. Int J Cancer 1987; 39: 45-9.

17 La Vecchia C, Negri E, Decarli A, D'Avanzo B, Franceschi S. Risk factors for heparocellular carcinoma in Northern Italy. Int $J$ Cancer 1988; 42: 872-6.

18 Weisburger J H, Wynder E L. Etiology of colorectal cancer with emphasis on mechanism of action and prevention. In: De Vita V T Jr, Hellman S, Rosenberg S A (eds.) Important Advances in Oncology. Philadelphia, Lippincott, 1987; 197-220.

19 Breslow N E, Enstrom J E. Geographic correlations between cancer mortality rates and alcohol-tobacco consumption in the United States. JNCI 1974; 53: 631-9.

20 Dean G, MacLennan R, McLoughlin H, Shelley E. Causes of death of blue-collar workers at a Dublin brewery, 1954-73, Br J Cancer 1979; 40: 581-9.

21 Wu A H, Paganini-Hill A, Ross R K, Henderson B E. Alcohol, physical activity and other risk factors for colorectal cancer: A prospective study. $\mathrm{Br} J$ Concer 1987; 55: 687-94.

22 Tuyns A J. Beer consumption and rectal cancer. Rev Epidemiol Santé Publique 1988; 36: 144-5.

23 Jensen $\mathrm{O} M$. Cancer morbidity and couses of death omong Danish brewery morkers. Lyon, International Agency for Research on Cancet, 1979.

24 Kabat G C, Howson C P, Wynder E L. Beer consumption and rectal cancer. Int J Epidemiol 1986; 15: 494-501.

25 Istituto Centrale di Statistica. Indogine statistica sulle condizioni di salule defla popolazione e sul ricorso oi servizi sanilari, novembre 1983. Rome, ISTAT, 1986.

26 Filippazzo M G, Aragona E, Cottone $M$ et al. Assessment of some 
risk factors for hepatocellular carcinoma: A case control gudy. Stat Med 1985; 4: 345-51.

27 US Office on Smoking and Health. The health consequences of smoking. Cancer. Report of the Surgeon General. Washington, D.C.: GPO, 1982.

28 Trichopoulos D, MacMahon B, Sparros L, Merikas C. Smoking and hepatitis B-negative primary hepatocellular carcinoma. JNCI 1980; 65: $111-4$.
29 Velema J P. Walker A M, Gold E B. Alcohol and pancreatic cancer. Insufficient epidemiologic evidence for a causal relationship. Epidemiol Rev 1986; 8: 28-41.

(Revised version received November 1988) 